\title{
Energy Consumption Modeling and Sensitivity Analysis for Deep-Argo Otarriinae Profiling Float
}

\author{
Weiwei Si $\mathbb{D}^{1,2}$ Yifan Xue, ${ }^{1,2,3,4}$ Yanjun Liu $\mathbb{D}^{1,2,3,4}$ Zhitong Li, ${ }^{1}$ and Gang Xue $\mathbb{D}^{1,2,3,4}$ \\ ${ }^{1}$ Institute of Marine Science and Technology, Shandong University, Qingdao 266200, China \\ ${ }^{2}$ Shenzhen Research Institute of Shandong University, Shenzhen 518057, China \\ ${ }^{3}$ School of Mechanical Engineering, Shandong University, Jinan 250061, China \\ ${ }^{4}$ Laboratory for Marine Geology, Qingdao National Laboratory for Marine Science and Technology, Qingdao 266200, China \\ Correspondence should be addressed to Yanjun Liu; lyj111ky@163.com and Gang Xue; xuegangzb@163.com
}

Received 30 October 2019; Revised 23 March 2020; Accepted 25 April 2020; Published 11 July 2020

Academic Editor: Luis J. Yebra

Copyright $(\odot 2020$ Weiwei Si et al. This is an open access article distributed under the Creative Commons Attribution License, which permits unrestricted use, distribution, and reproduction in any medium, provided the original work is properly cited.

\begin{abstract}
Deep-Argo Otarriinae profiling float is a new type of Argo profiling float that has a maximum diving depth of more than 4,000 $\mathrm{m}$. It can collect ocean scientific data all-weather and uninterruptedly, which provides reliable data support for the global ocean scientific research. The working time of Deep-Argo profiling float is an important indicator of its practicality and economy, and it is clear that the energy consumption is a key factor in determining its working time. In this paper, the single profile energy consumption model with 19 parameters of Deep-Argo Otarriinae is established and the main effect indices and total effect indices of the energy consumption parameters to energy consumption are calculated using Sobol' sensitivity analysis method, aiming to find the parameters that have the greatest impact on energy consumption. The results show that the gliding angle, the diving depth, and the gliding speed have a significant impact on energy consumption of Deep-Argo Otarriinae. The results of simulation have a good match with the actual application and have certain reference significance for the determination of the design parameters and the selection of the navigation parameters. This paper also provides a new idea of multiparameter energy consumption modeling for underwater equipment using buoyancy regulation.
\end{abstract}

\section{Introduction}

Argo profiling float is a typical type of ocean observation platform, which provides continuous observations of ocean temperature and salinity versus pressure, from the sea surface to the maximum design depth of 2,000 $\mathrm{m}$ [1]. It can be equipped with sophisticated sensors and is capable of collecting scientific data under difficult and harsh conditions. It is the key equipment of Array for Real-time Geostrophic Oceanography, which is also named as the ocean observations with the global Argo array [2]. Compared with other ocean observation platforms, Argo profiling float has a simple structure and a long working time. It can periodically float to the sea surface to exchange data with the shore station via satellite. The temporal coverage of Argo data is much better than ship monitoring data [3]. Argo profiling float has become the primary source of near-real-time data for ocean and atmospheric services and high quality data for climate research [4]. The data from Argo have been used to study climate variability in the Norwegian Sea and interpret the global oceanic heat transport $[5,6]$.

Deep-Argo Otarriinae profiling float is a new type of Argo profiling float that has a maximum diving depth of more than $4,000 \mathrm{~m}$ while the conventional one has a maximum diving depth of 2,000 m. Deep-Argo extends the observation range of Argo profiling float to the sea floor and accurately measures variation of seawater parameters in the deep sea areas $[7,8]$. At present, four models of Deep-Argo floats have been developed and are currently in use, including APEX profiling float and Deep-SOLO float of the United States, Deep-ARVOR profiling float of France, and Deep NINJA profiling float of Japan [9-12]. China successfully developed the first set of Argo float prototypes in 2003 and completed the sea trial [13]. Just like other deep 
ocean exploration equipment, the performance of DeepArgo is also constrained by energy issues. The Deep-ARVOR profiling float developed by Ifremer extends the current operational depth down to $4,000 \mathrm{~m}$, and the results of the atsea experiments showed that the float could work for nine months at a rate of one cycle every two days in the West European Basin [14]. The energy supply of Deep-Argo profiling float comes from the disposable or rechargeable batteries it carries. The battery capacity limits the operating time and navigation range of Deep-Argo. Therefore, reducing the power consumption of the Argo profiling float is of great significance for improving the performance of DeepArgo. Low-power technology has become one of the research trends of underwater vehicles. Woithe and Kremer described a new sensor management technique that makes use of published thermocline detection and tracking algorithms to simulate the triggering of sensors while a vehicle is within the thermocline instead of modifying its flight profile. This sensor management technique has also been successfully used in two at-sea trials with Slocum Glider and the energy savings of up to $50 \%$ and $63 \%$, respectively [15]. Yu established an applied mathematical model of Sea-Wing underwater glider that relates the gliding range to steady gliding motion parameters and energy consumption. In addition, $\mathrm{Yu}$ optimized the steady gliding motion parameters and developed a sensor scheduling strategy to increase the gliding range of Sea-Wing underwater glider [16]. Zhou presented a new Constant-Time Surfacing $A^{*}$ algorithmbased iterative path planning algorithm to address underwater glider with variable speeds which can maximize the usage of the favourable currents. From the simulation of hyperbolic currents field, the novel variable speed scheme can get a path with lesser energy cost compared with constant speed [17]. Kelasidi investigated the power consumption of different underwater robotic systems and compared the energy efficiency of different robots depending on the desired motion. In particular, Kelasidi compared the energy efficiency of underwater snake robots, which can provide both inspection and intervention capabilities and thus are interesting candidates for the nextgeneration inspection and intervention AUVs and the simulation results showed that the underwater snake robots are more energy efficient for all compared motion modes [18]. Lu proposed and validated a practical path planning algorithm considering both energy efficiency and estimation accuracy for the AUV. Besides, an optimal estimation strategy was developed based on Kalman Filter in order to minimize the filter uncertainty and energy consumption [19]. Yao proposed an energy consumption reduction method based on MPC (model predictive control) with a quadratic energy consumption term added into the cost function for AUV's trajectory tracking control. The simulation results showed that the proposed MPC method is feasible and effective for energy consumption reduction of AUV even with great model uncertainty [20].

In this paper, the $4,000 \mathrm{~m}$ Deep-Argo Otarriinae profiling float developed by Shandong University is regarded as the research object [21]. The shape and the main parameters are shown in Figure 1. Two sea trials with Deep-Argo
Otarriinae have been conducted successfully near the Mariana Trench since 2017. When the target working depth is $4000 \mathrm{~m}$, the number of working profiles of Deep-Argo Otarriinae is more than 120 . The remaining parts of this paper are organized as follows. In Section 2, the $4,000 \mathrm{~m}$ Deep-Argo Otarriinae profiling float developed by Shandong University is introduced. In Section 3, the energy consumption model of Deep-Argo Otarriinae is established. In Section 4, the parameters in the energy consumption model are determined. The sensitivity analysis of energy consumption parameters is conducted in Section 5. Finally, conclusions are provided in Section 6.

\section{Deep-Argo Otarriinae Profiling Float}

2.1. Workflow of Deep-Argo Otarriinae. The Deep-Argo Otarriinae profiling float developed by Shandong University is mainly composed of pressure chamber, hydraulic system, communication and positioning unit, embedded control system, and sensors. The pressure chamber provides a sealed and waterproof environment for the internal subsystem. The hydraulic system adjusts the volume of Deep-Argo Otarriinae by controlling the hydraulic oil to flow in or flow out the outer oil bladder to achieve buoyancy adjustment. The communication and positioning unit is mainly composed of a global positioning system, Iridium communication module, and wireless communication module. Deep-Argo Otarriinae can switch the communication mode according to the distance between Deep-Argo Otarriinae and the shore station and the mission demand. The embedded control system manages tasks in real time, performs status monitoring, and data analysis. The sensors are responsible for monitoring the operational status and data acquisition of the Deep-Argo Otarriinae profiling float.

The general single profile workflow of Deep-Argo Otarriinae is shown in Figure 2, which is mainly composed of communication and waiting stage on the sea surface, diving preparation stage, diving stage, drift stage, ascending preparation stage, and ascending stage [2]. However, in the drift stage, Deep-Argo Otarriinae is in standby state and the standby current is very small, about microampere level. So the energy consumption of the drift stage can be simplified in the workflow from the perspective of energy consumption analysis. The simplified single profile workflow of DeepArgo Otarriinae is shown in Figure 3, which excludes drift stage. When Deep-Argo Otarriinae is in the communication and waiting stage, the current position of Deep-Argo Otarriinae is determined by GPS and the information is exchanged with the deck operator through Iridium or wireless communication. When Deep-Argo Otarriinae receives the diving command, Deep-Argo Otarriinae adjusts itself to the negative buoyancy through the hydraulic system during the diving preparation stage, and then Deep-Argo Otarriinae starts to dive. When Deep-Argo Otarriinae reaches the target depth, it adjusts itself to the positive buoyancy through the hydraulic system during the ascending preparation stage, thereby starting to ascend until reaching the water surface. At this point, a single-profile workflow of Deep-Argo Otarriinae ends and then Deep- 


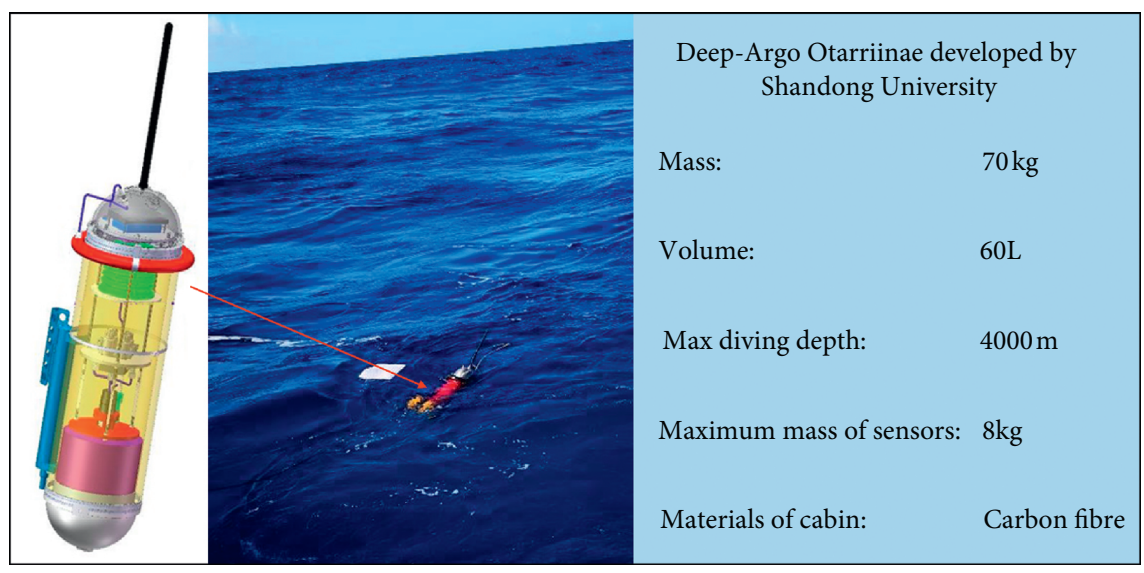

FIgURE 1: 4000 m Deep-Argo Otarriinae developed by Shandong University.

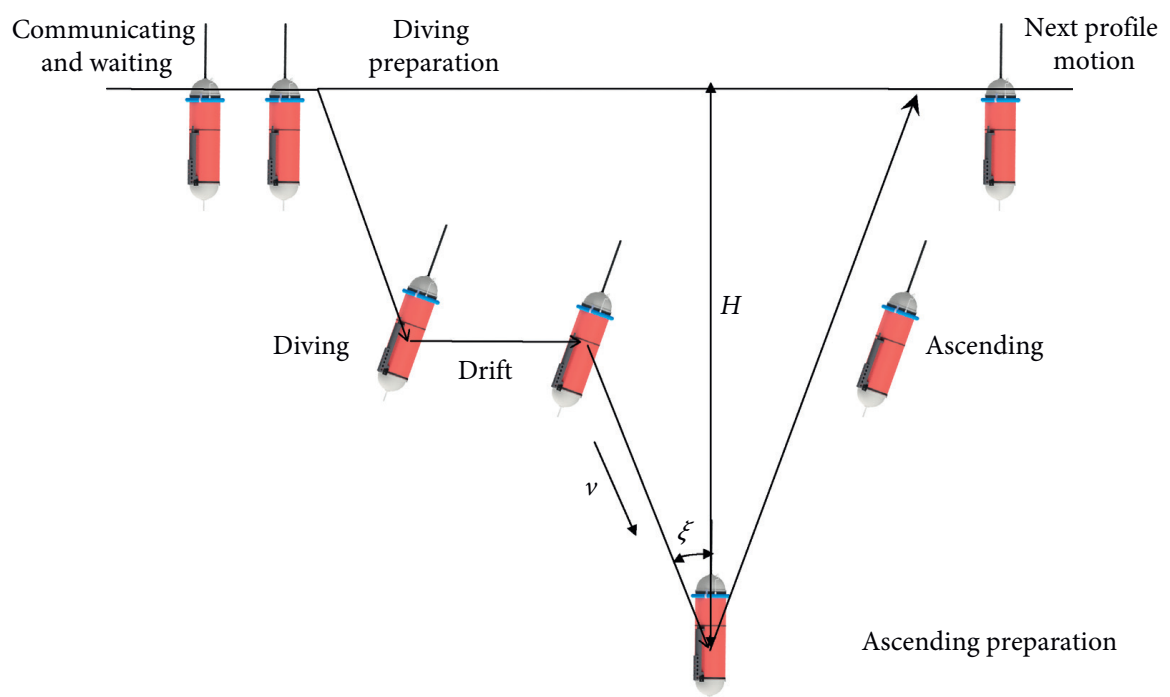

Figure 2: The general single profile workflow of Deep-Argo Otarriinae.

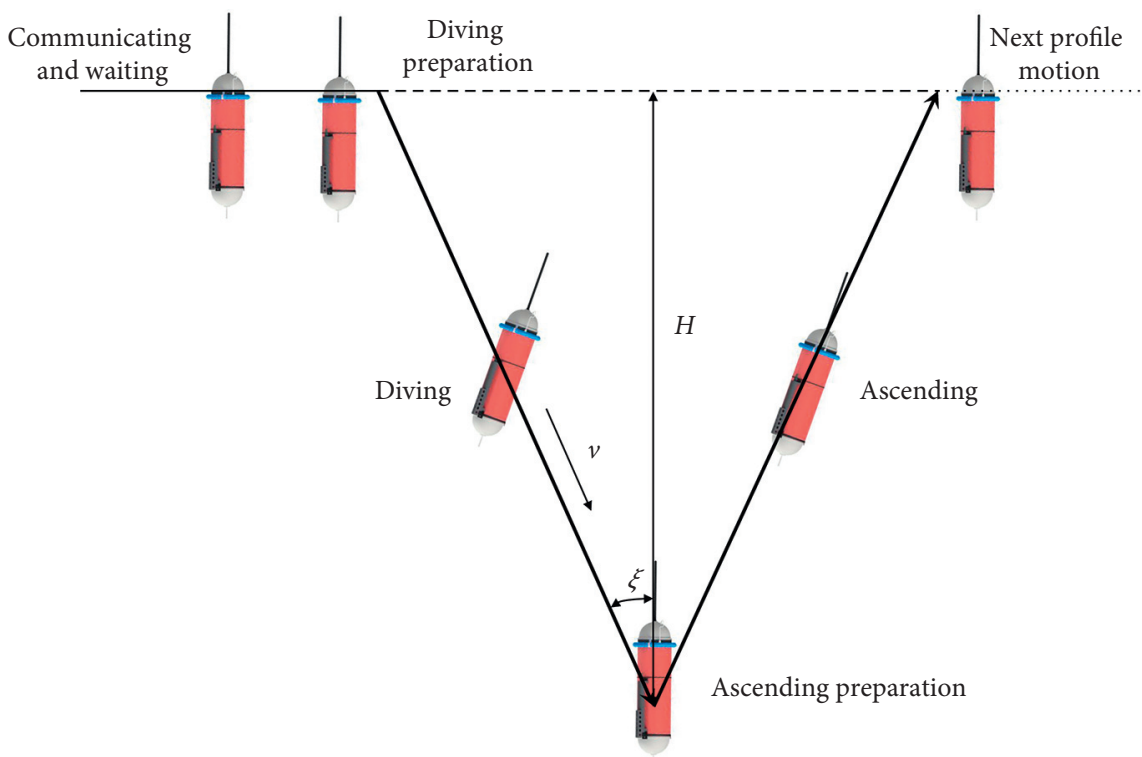

Figure 3: The simplified single profile workflow of Deep-Argo Otarriinae. 
Argo Otarriinae enters the communication and waiting stage of the next workflow. Figure 4 shows the operating state of each subsystem in a single profile, in which the embedded control system always maintains the operating state, and other subsystems just operate when needed.

2.2. The Kinetic Model of Deep-Argo Otarriinae. Before building an energy consumption model, we need to find out the relationship between the parameters of Deep-Argo Otarriinae. The kinetic parameters and force analysis of Deep-Argo Otarriinae during steady gliding are shown in Figure 5, in which $O-X Z$ denotes the inertial coordinate system; $B-e_{1} e_{3}$ is the body coordinate system; $B$ is the buoyancy center of Deep-Argo Otarriinae; $\alpha$ is the attack angle; $\theta$ is the pitch angle; $\xi$ is the gliding angle; $D, L$ are the drag force and lift force of Deep-Argo Otarriinae, respectively; $\bar{m} g$ is net buoyancy force; and $v$ is the gliding speed of Deep-Argo Otarriinae in the body coordinate system.

The geometric relationships and force balance relationships of the steady gliding motion can be expressed as

$$
\begin{aligned}
-\bar{m} g \sin \theta-L \cos \alpha+D \sin \alpha & =0, \\
-\bar{m} g \cos \theta-L \sin \alpha+D \cos \alpha & =0, \\
\xi & =\theta-\alpha, \\
L & =\bar{m} g \cos \xi, \\
D & =\bar{m} g \sin \xi .
\end{aligned}
$$

The drag force and lift force of Deep-Argo Otarriinae can be expressed as

$$
\begin{aligned}
& D=\left(K_{D 0}+K_{D} \alpha^{2}\right) v^{2}, \\
& L=\left(K_{L 0}+K_{L} \alpha\right) v^{2},
\end{aligned}
$$

where $K_{D 0}$ and $K_{D}$ are drag coefficients, $K_{L 0}$ and $K_{L}$ are lift coefficients.

Applying the drag force and lift force obtained by equation (4) and (5) into equation (6) and (7), the following equation is obtained:

$$
\alpha=\frac{1}{2} \frac{K_{L}}{K_{D}} \tan \xi\left(-1+\sqrt{1-4 \frac{K_{D}}{K_{L}^{2}}} \cot \xi\left(K_{D 0} \cot \xi-K_{L 0}\right)\right) .
$$

It can be seen from equation (8) that the attack angle $\alpha$ is a function of the gliding angle $\xi$ and the hydrodynamic parameters when Deep-Argo Otarriinae is in steady gliding state.

\section{Energy Consumption Model of Deep- Argo Otarriinae}

Combining the single profile workflow of Deep-Argo Otarriinae and the operating state of each subsystem, the energy consumption analysis of each subsystem is performed, respectively. As shown in Figure 3, the energy consumption of Deep-Argo Otarriinae in a single profile mainly includes three parts: energy consumption of hydraulic system, energy consumption of positioning and communication unit, and the energy consumption of embedded control system and sensors.

3.1. Energy Consumption of Hydraulic System. The energy consumption of hydraulic system mainly includes the energy consumption of the servo motor and the solenoid valve. There are two buoyancy adjustment stages in a single profile workflow, which are diving preparation stage and ascending preparation stage. In the diving preparation stage, the hydraulic oil is driven to the inner oil bladder from outer oil bladder by the plunger pump on the sea surface, the volume of the outer oil bladder will shrink, and buoyancy force on the equipment will decrease, so Deep-Argo Otarriinae starts to dive. Conversely, in the ascending preparation stage, the hydraulic oil is driven to the outer oil bladder from inner oil bladder by the plunger pump, the volume of the outer oil bladder will swell, and buoyancy force on the equipment will increase, so Deep-Argo Otarriinae starts to ascend. The hydraulic schematic diagram of Deep-Argo Otarriinae is shown in Figure 6.

Total energy consumption of the hydraulic system in a single profile can be described as

$$
\begin{aligned}
Q_{n} & =P_{\text {hydra } 0} \cdot t_{1}+P_{\text {hydra }}(H) \cdot t_{2}, \\
t_{1} & =\frac{\Delta V}{q_{\text {pump } 0}}, \\
t_{2} & =\frac{\Delta V}{q_{\text {pumpH }}},
\end{aligned}
$$

where $Q_{n}$ is the energy consumption of hydraulic system, $P_{\text {hydra0 }}$ is the power of the hydraulic system when Deep-Argo Otarriinae is in the diving preparation stage, $t_{1}$ is the working time of the hydraulic system in the diving preparation stage, $H$ is the target working depth of Deep-Argo Otarriinae, $P_{\text {hydra }}(H)$ is the power of the hydraulic system in the ascending preparation stage, $t_{2}$ is the working time of the hydraulic system in the ascending preparation stage, $\Delta V$ is the volume change of the outer oil bladder, $q_{\text {pump } 0}$ is the flow rate of the plunger pump when working in the diving preparation stage, and $q_{p u m p H}$ is the flow rate of the plunger pump in the ascending preparation stage.

Equation (9) can also be described as

$$
Q_{n}=P_{\text {hydra } 0} \cdot \frac{\Delta V}{q_{\text {pump0 }}}+P_{\text {hydra }}(H) \cdot \frac{\Delta V}{q_{\text {pumpH }}} .
$$

From equations (1) and (2), we can get the following equation:

$$
\bar{m} g=-L \sin \xi+D \cos \xi .
$$

According to the relationship between the buoyancy and the volume change, the following equation can be obtained easily: 


\begin{tabular}{|c|c|c|c|c|c|c|}
\hline Stage & $\begin{array}{c}\text { Hydraulic } \\
\text { system }\end{array}$ & $\begin{array}{l}\text { Communicat } \\
\text { ion\& GPS }\end{array}$ & $\begin{array}{c}\text { Embedded } \\
\text { control } \\
\text { System } \\
\end{array}$ & $\begin{array}{c}\text { Full-range } \\
\text { operating } \\
\text { Sensors } \\
\end{array}$ & $\begin{array}{c}\text { Sensors } \\
\text { controlled by } \\
\text { depth }\end{array}$ & CTD \\
\hline \multicolumn{7}{|l|}{$\begin{array}{l}\text { Communicating } \\
\text { \& waiting }\end{array}$} \\
\hline \multicolumn{7}{|l|}{$\begin{array}{l}\text { Diving } \\
\text { Preparation }\end{array}$} \\
\hline \multicolumn{7}{|l|}{ Diving } \\
\hline \multicolumn{7}{|l|}{$\begin{array}{l}\text { Ascending } \\
\text { preparation }\end{array}$} \\
\hline \multicolumn{7}{|l|}{ Ascending } \\
\hline $\begin{array}{l}\text { Preparation for } \\
\text { next profilre } \\
\text { motion }\end{array}$ & & & & & & \\
\hline
\end{tabular}

FIGURE 4: The operating state of each subsystem in a single profile.

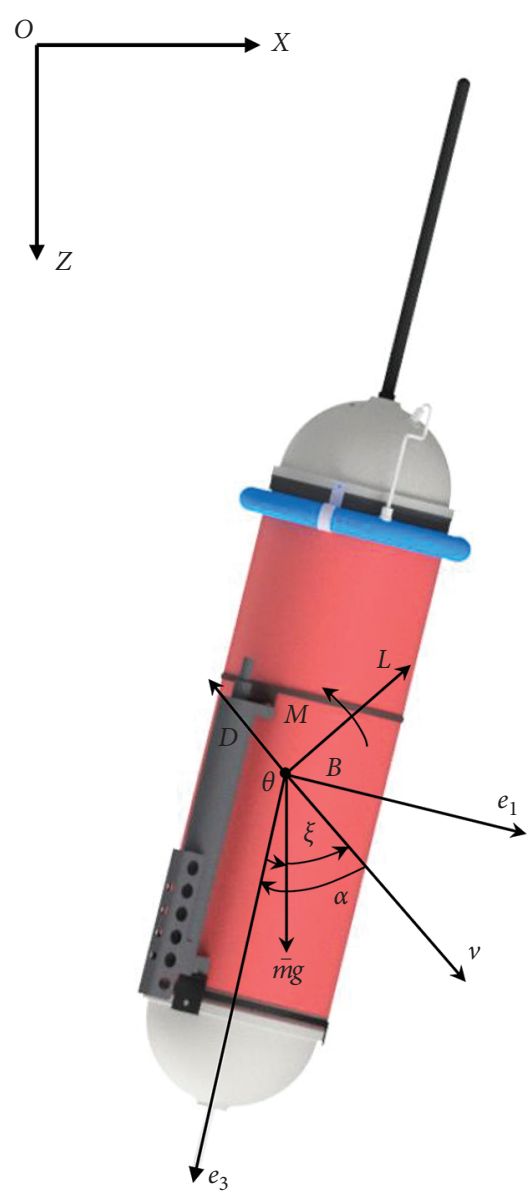

Figure 5: Steady gliding state of Deep-Argo Otarriinae.

$$
\bar{m}=-\rho_{\text {water }} \Delta V,
$$

where $\rho_{\text {water }}$ is the density of the sea water.
By substituting equations (6), (7), (13), and (14) into equation (12), total energy consumption of the hydraulic system in a single profile can also be described as

$$
\begin{aligned}
Q_{n}= & \frac{\left(\left(K_{L 0}+K_{L} \alpha\right) \sin \xi-\left(K_{D 0}+K_{D} \alpha^{2}\right) \cos \xi\right) v^{2}}{\rho_{\text {water }} g} \\
& \cdot\left(\frac{P_{\text {hydra0 } 0}}{q_{\text {pump } 0}}+\frac{P_{\text {hydra }}(H)}{q_{\text {pumpH }}}\right) .
\end{aligned}
$$

\subsection{Energy Consumption of Communication and Positioning} Unit. Since Deep-Argo Otarriinae completes the communication and positioning process on the sea surface, the energy consumption in this process is only related to the power and running time of relevant electronic equipment and has no obvious relationship with the navigation parameters and design parameters of Deep-Argo Otarriinae. Energy consumption generated by positioning and communication unit in a single profile can be described as

$$
Q_{f}=P_{f} t_{f},
$$

where $Q_{f}$ is energy consumption of communication and positioning unit, $P_{f}$ is the power of the electronic equipment used in communication and waiting stage, and $t_{f}$ is the time of communication and waiting stage.

\subsection{Energy Consumption of Embedded Control System and the} Sensors. Deep-Argo Otarriinae profiling float can be equipped with a variety of sensors. Sensors can be divided into two types based on different operating modes: fullrange operating sensors and intermittent operating sensors. The sensors embedded in our prototype are shown in Table 1 . In addition, our prototype also reserves three sensor interfaces, which can be embedded with different sensors according to different tasks. 


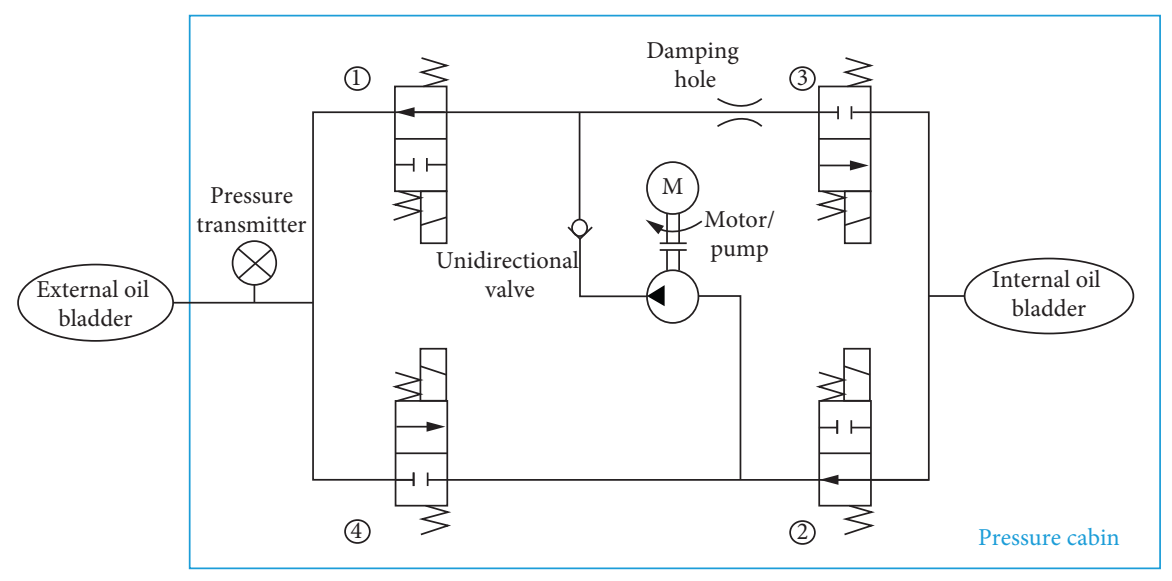

(1)-(2): Solenoid valve

FIgURE 6: The hydraulic schematic diagram of Deep-Argo Otarriinae.

Table 1: Sensors embedded in Deep-Argo Otarriinae

\begin{tabular}{lcc}
\hline $\begin{array}{l}\text { Full-range } \\
\text { operating sensors }\end{array}$ & $\begin{array}{c}\text { Sensors } \\
\text { controlled by } \\
\text { depth }\end{array}$ & CTD \\
\hline $\begin{array}{l}\text { Pressure } \\
\text { transmitter }\end{array}$ & Altimeter & SBE 37-SMMicroCAT \\
$\begin{array}{l}\text { Linear } \\
\text { displacement }\end{array}$ & CT(P) recorder \\
sensor & & \\
\hline
\end{tabular}

The full-range operating sensors mean that sensors operate throughout the single profile (excluding the communication and waiting stage). For example, the pressure transmitter monitors the change of pressure throughout the whole workflow. The CTD embedded in our prototype is SBE 37-SMMicroCAT CT(P) Recorder which is self-contained. The sampling interval of CTD is $6 \mathrm{~s}$ to $6 \mathrm{~h}$, and the sampling time is $1.8 \mathrm{~s}$ to $2.6 \mathrm{~s}$. The energy carried by CTD can collect 960,000 data. The energy consumed by CTD is only used to read the data collected by CTD and not to drive the pump and electronic components inside CTD. According to the specifications of the Argo organization, CTD is not open all the way, but only during ascending stage. In the simplified workflow of Deep-Argo Otarriinae, the buoyancy adjustment and hydrodynamic coefficient of Deep-Argo Otarriinae are basically the same in the diving stage and ascending stage. In other words, the values of the factors that affect the speed of ascent and descent are similar, so the speed of ascent and descent is basically the same and the time of the diving stage and ascending stage is almost identical. In order to facilitate the calculation, we include CTD in the full-range operating sensors. The energy consumption of the full-range operating sensors can be described as

$$
\begin{aligned}
Q_{t 1}= & P_{t 1} \cdot \frac{t_{3}}{2}+\left(P_{t 1}+P_{\mathrm{CTD}}\right) \cdot \frac{t_{3}}{2}=\left(2 P_{t 1}+P_{\mathrm{CTD}}\right) \\
& \cdot \frac{H}{\left|v_{Z}\right|}=\left(2 P_{t 1}+P_{\mathrm{CTD}}\right) \cdot \frac{H}{|v \cos \xi|}
\end{aligned}
$$

where $Q_{t 1}$ is the energy consumption of the full-range operating sensors, $P_{t 1}$ is the sum of the average power of the full-range operating sensors excluding CTD, $P_{\mathrm{CTD}}$ is the power of CTD, $t_{3}$ is the time of the diving stage or ascending stage, and $v_{Z}$ is the vertical component of the gliding speed.

The intermittent operating sensors mean that sensors operate at regular depth intervals in order to save energy or to meet measurement requirements. The specific sampling process of intermittent operating altimeter is shown in Figure 7, and the energy consumption of the intermittent operating sensors in the single profile can be described as

$$
Q_{t 2}=\sum_{i=1}^{j} \frac{2 H \Delta t_{i} P_{s i}}{\Delta h_{i}+\Delta t_{i}|v \cos \xi|}
$$

where $Q_{t 2}$ is the energy consumption of the intermittent operating sensors, $j$ is the number of intermittent operating sensors carried by Deep-Argo Otarriinae, $\Delta t_{i}$ is the time of single operation of $i-t h$ sensor, $\Delta h_{i}$ is the height interval at which the sensor is turned on, and $P_{s i}$ is the power of single operation of $i-t h$ sensor.

The embedded control system keeps working during the entire profile, including the communication and waiting stage. The energy consumption of this part can be described as

$$
Q_{t 3}=P_{t 3}\left(t_{3}+t_{f}\right)=P_{t 3}\left(\frac{2 H}{|v \cos \xi|}+t_{f}\right),
$$

where $Q_{t 3}$ is the energy consumption of the embedded control system, and $P_{t 3}$ is the power of the embedded control system.

In summary, the total energy consumption of control system and sensors can be described as

$$
\begin{aligned}
Q_{t}= & Q_{t 1}+Q_{t 2}+Q_{t 3}=\left(2 P_{t 1}+P_{\mathrm{CTD}}\right) \cdot \frac{H}{|v \cos \xi|} \\
& +\sum_{i=1}^{j} \frac{2 H \Delta t_{i} P_{s i}}{\Delta \Delta+\Delta t_{i}|v \cos \xi|}+P_{t 3}\left(\frac{2 H}{|v \cos \xi|}+t_{f}\right)
\end{aligned}
$$




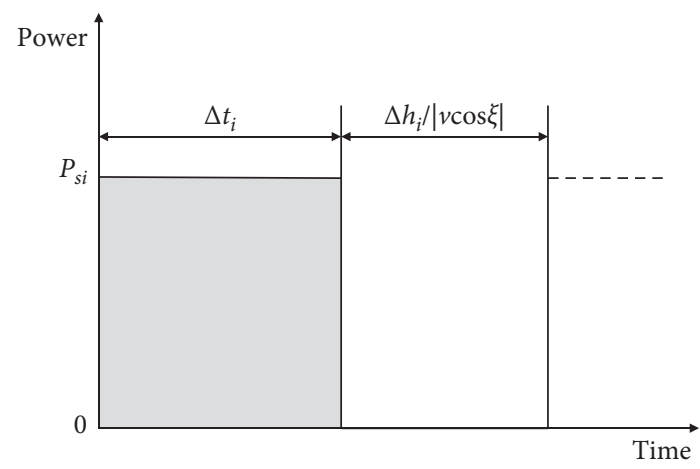

FIGURE 7: The specific sampling process of intermittent operating altimeter.

where $Q_{t}$ is the energy consumption of embedded control system and sensors.

3.4. The Energy Consumption Model in a Single Profile. The total energy consumption model in a single profile can be obtained by adding the energy consumption of each part mentioned above, which can be described as

$$
\begin{aligned}
Q= & f\left(K_{L 0}, K_{L}, K_{D 0}, K_{D}, \xi, v, P_{\text {hydra } 0}, P_{\text {hydra }}(H),\right. \\
& \left.q_{\text {pump } 0}, q_{\text {pumpH }}, H, P_{t 1}, P_{s i}, P_{t 3}, P_{f}, t_{f}, \Delta t_{i}, \Delta h_{i}\right) \\
= & Q_{n}+Q_{f}+Q_{t} \\
= & \frac{\left(\left(K_{L 0}+K_{L} \alpha\right) \sin \xi-\left(K_{D 0}+K_{D} \alpha^{2}\right) \cos \xi\right) \cdot v^{2}}{\rho_{\text {water }} g} \\
& \cdot \frac{P_{\text {hydra } 0}}{q_{\text {pump } 0}}+\frac{P_{\text {hydra }}(H)}{q_{\text {pumpH }}}+P_{f} t_{f}+\left(2 P_{t 1}+P_{\mathrm{CTD}}\right) \\
& \cdot \frac{H}{|v \cos \xi|}+\sum_{i=1}^{j} \frac{2 H \Delta t_{i} P_{s i}}{\Delta h_{i}+\Delta t_{i}|v \cos \xi|}+P_{t 3}\left(\frac{2 H}{|v \cos \xi|}+t_{f}\right) .
\end{aligned}
$$

The energy consumption model of Deep-Argo Otarriinae in a single profile has the following characteristics:

(1) There are many parameters involved, including hydrodynamic parameters, hydraulic system parameters, navigation parameters, main design parameters, and other 19 parameters.

(2) There is a coupling relationship between the energy consumption of each subsystem. The energy consumption of each subsystem in the model is related to multiple parameters, and changes in some parameters will lead to changes of multiple subsystems in energy consumption.

(3) The energy consumption model is highly nonlinear.

\section{Determination of Energy Consumption Parameters}

Some parameters are not determined in the design of DeepArgo Otarriinae. Their values will show a certain change law with the change of working environment, so they need to be obtained through experiment or simulation. Another part of the parameters are determined in the design and their parameter values are shown in Table 2 .

4.1. Determination of Hydraulic System Parameters. As shown in Figure 8, in order to obtain the change law of the power and flow of hydraulic system during the diving preparation stage and the ascending preparation stage, we used a hydraulic booster system to simulate the highpressure underwater environment and tested the operation of the hydraulic system under different pressures.

Through the test of Deep-Argo Otarriinae hydraulic system, we finally obtained the power of hydraulic system in the diving preparation stage and ascending preparation stage as shown in Figure 9.

It can be seen from Figure 9(a) that the power of hydraulic system $P_{\text {hydra0 }}$ is about $66 \mathrm{~W}$ when it is stable in the diving preparation stage. The power of the hydraulic system in the ascending preparation stage at different target depth is fitted by curve, which is shown in Figure 9(b). Fitted curve equation is as follows:

$$
P_{\text {hydra }}(H)=7.08 H^{2}+4.36 H+11.96 .
$$

According to the fitting results, the complex correlation coefficient $R^{2}$ of the fitting curve is 0.9678 , which fully meets the accuracy requirement.

The flow of the hydraulic system in the test is shown as Figure 10.

From Figure 10(a), we can calculate that the value of flow $q_{\text {pump } 0}$ of hydraulic system is about $0.119 \mathrm{~L} / \mathrm{min}$ in the diving preparation stage. It can be seen from Figure 10(b) that under different working pressures, the flow $q_{\text {pumpH }}$ of the hydraulic system is stabilized at $0.06 \mathrm{~L} / \mathrm{min}$ in the ascending preparation stage.

The power and flow of hydraulic system is determined by the performance and design parameters of the system, which can be considered as a fixed value and sensitivity analysis is not required.

4.2. Determination of Hydrodynamic Parameters. There are several methods that will produce results for hydrodynamic parameters based on a given geometry. The methods include analytical, experimental, computational, and semiempirical approaches [22]. In this paper, computational fluid dynamics (CFD) is used to solve the viscous hydrodynamic parameters, and FLUENT is used to calculate the resistance, lift force, and torque of Deep-Argo Otarriinae in steady gliding when the angle of attack is $0^{\circ}, 2^{\circ}$, and $4^{\circ}$ and gliding speed is $0.1 \mathrm{~m} / \mathrm{s}, 0.3 \mathrm{~m} / \mathrm{s}$, and $0.5 \mathrm{~m} / \mathrm{s}$, respectively. The hydrodynamic parameters of Deep-Argo Otarriinae in steady gliding are calculated using the least square method, as shown in Table 3.

The hydrodynamic parameters are necessary and important to measure the hydrodynamic performance of DeepArgo Otarriinae. The variation of the hydrodynamic parameters has a very important impact on the energy 
TABle 2: Parameters determined in the design.

\begin{tabular}{lcc}
\hline Parameters & Value & Unit symbol \\
\hline $\mathbf{P}_{\mathbf{t} 1}$ & 0.107 & $\mathrm{~W}$ \\
$\mathbf{P}_{\text {CTD }}$ & 0.01 & $\mathrm{~W}$ \\
$\mathbf{P}_{\mathbf{t} 3}$ & 1 & $\mathrm{~W}$ \\
$\mathbf{P}_{\mathbf{f}}$ & 1 & $\mathrm{~W}$ \\
$\mathbf{P}_{\mathbf{s} 1}$ & 1.92 & $\mathrm{~W}$ \\
$\boldsymbol{\rho}_{\text {water }}$ & 1025 & $\mathrm{~kg} / \mathrm{m}^{3}$ \\
$\mathbf{g}$ & 9.8 & $\mathrm{~N} / \mathrm{kg}$ \\
\hline
\end{tabular}

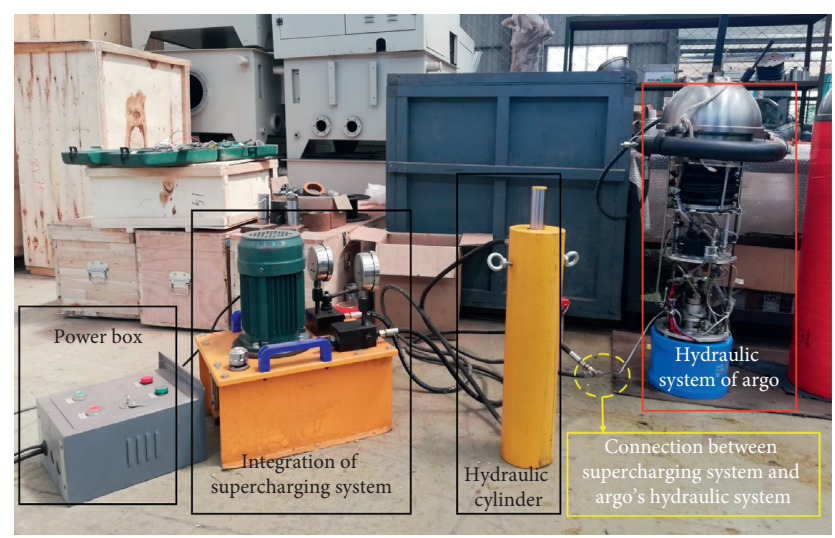

FIgURE 8: Hydraulic booster system for testing.

consumption and voyage of Deep-Argo Otarriinae, so sensitivity analysis for hydrodynamic parameters is needed. For the convenience of analysis, we assume that each hydrodynamic coefficient can fluctuate by $20 \%$ compared with the prototype and follows the uniform distribution within the respective value range.

4.3. Determination of Navigation Parameters. The navigation parameters are arguments that the operator needs to set directly or indirectly and are also the key to measure the underwater operation state of Deep-Argo Otarriinae. Therefore, it is necessary to study the influence of navigation parameters on the energy consumption and voyage of DeepArgo Otarriinae.

(1) Gliding speed $v$

The gliding speed of the Deep-SOLO float is about $0.06 \mathrm{~m} / \mathrm{s}$, the gliding speed of the Deep-SOLO 2 float is about $0.12 \mathrm{~m} / \mathrm{s}$, and the gliding speed of the ArvorC profiling float is about $0.15-0.20 \mathrm{~m} / \mathrm{s}[23,24]$. Therefore, we set the gliding speed of Deep-Argo Otarriinae as $0.05-0.20 \mathrm{~m} / \mathrm{s}$ when it moves steadily, and it follows uniform distribution within this interval.

(2) Gliding angle $\xi$

According to equation (1) and equation (2), we can get the equation as follows:

$$
L \cos \xi+D \sin \xi=0 .
$$

By substituting equations (4) and (5) into equation (33), we can get equation as follows:

$$
K_{D} \sin \xi \cdot \alpha^{2}+K_{L} \cos \xi \cdot \alpha+K_{L 0} \cos \xi+K_{D 0} \sin \xi=0 .
$$

The attack angle $\alpha$ is a certain value when Deep-Argo Otarriinae moves steadily, that is to say, equation (34) has a solution and

$\left(K_{L} \cos \xi\right)^{2}-4 K_{D} \sin \xi\left(K_{L 0} \cos \xi+K_{D 0} \sin \xi\right) \geq 0$.

We stipulate that the gliding angle of Deep-Argo Otarriinae is within $(-\pi / 2,0) \cup(0, \pi / 2)$, but in order to ensure the economicality of navigation, generally the gliding angle is within $(-\pi / 4,0) \cup(0, \pi / 4)$. Therefore, the gliding angle needs to meet the following equation for keeping stable motion:

$$
\left(\tan ^{-1}\left(\frac{-K_{L 0} K_{D}-\sqrt{K_{L 0}^{2} K_{D}^{2}+K_{L}^{2} K_{D 0}}}{2 K_{D 0} K_{D}}\right), 0\right) \cup\left(0, \tan ^{-1}\left(\frac{-K_{L 0} K_{D}+\sqrt{K_{L 0}^{2} K_{D}^{2}+K_{L}^{2} K_{D 0}}}{2 K_{D 0} K_{D}}\right)\right)
$$

Substituting the hydrodynamic parameters shown in Table 3 into equation (26), we finally determine that the gliding angle of Deep-Argo Otarriinae is within $\left(-7.76^{\circ}, 0\right) \cup\left(0,7.51^{\circ}\right)$. Under the condition that the velocity of ocean current is almost constant, the gliding angle of Deep-Argo Otarriinae is set uniformly distributed in the above range.

(3) Diving depth $H$

The diving depth of Deep-Argo Otarriinae is determined by the operator. The diving depth of DeepArgo Otarriinae ranges from 0 to $4,000 \mathrm{~m}$, and $H$ can be considered to be uniformly distributed within this range.

(4) Communication and waiting time $t_{f}$

Since the satellite signal intensity will be affected by weather condition, marine environment, satellite operating state, and other factors, and the operator may perform additional data exchange operations with Deep-Argo Otarriinae according to the task requirements, the communication and waiting time will have a certain randomness. As a matter of experience, positioning and communication time $t_{f}$ is 


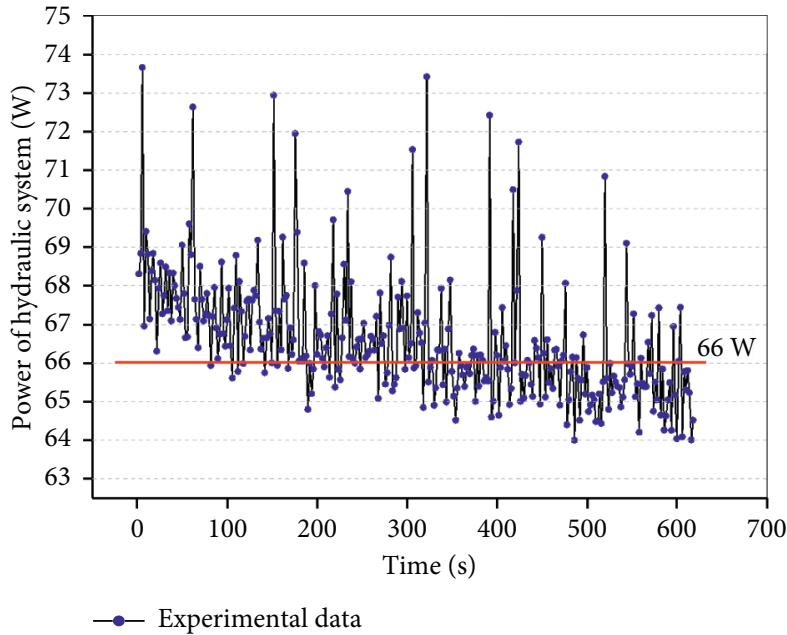

(a)

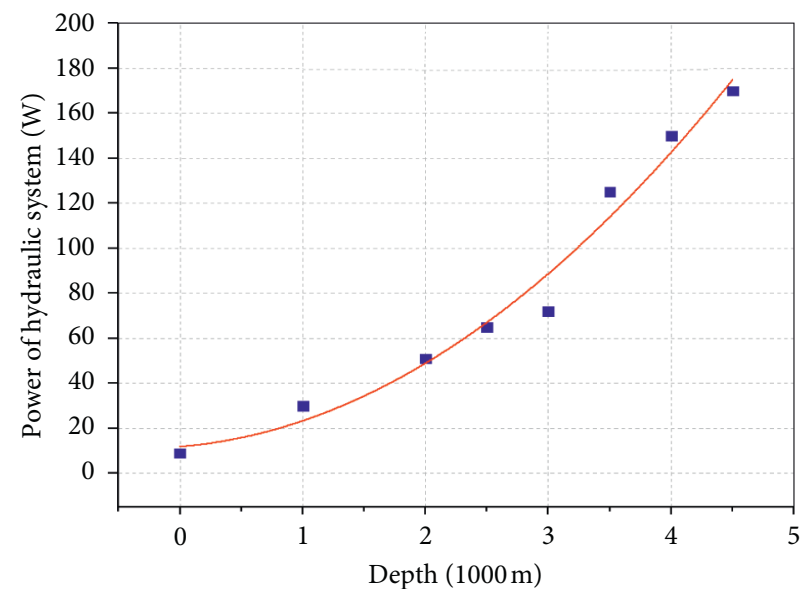

- Experimental results

_ Fitted curve

Figure 9: Power of hydraulic system in the test. (a) Volume change of external oil bladder in the diving preparation stage. (b) Power of hydraulic system in the ascending preparation stage.

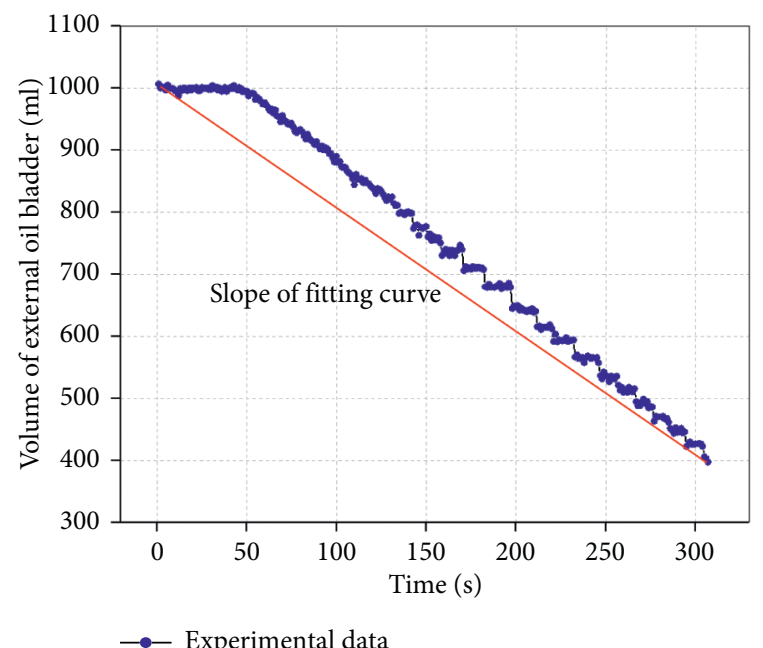

(a)

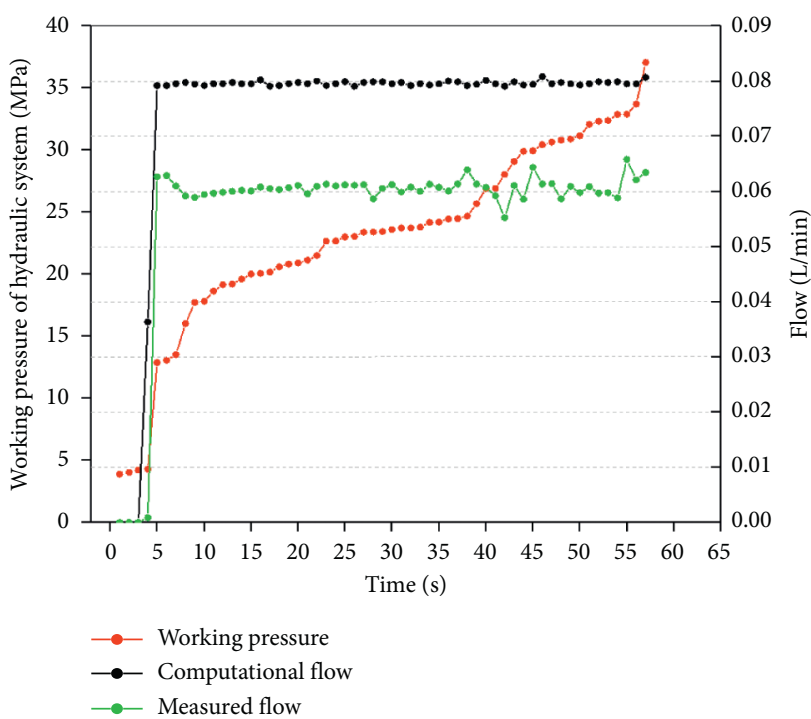

(b)

Figure 10: Flow of hydraulic system in the test. (a) Diving preparation stage. (b) Ascending preparation stage.

TABLE 3: Results for hydrodynamic parameters.

\begin{tabular}{lcccc}
\hline Hydrodynamic parameters & $\mathbf{K}_{\mathbf{D} 0}$ & $\mathbf{K}_{\mathbf{D}}$ & $\mathbf{K}_{\mathbf{L} 0}$ & $\mathbf{K}_{\mathbf{L}}$ \\
\hline Value & 23.8 & 1156.1 & 0.1056 & 44.4792 \\
\hline
\end{tabular}

within $600-1200 \mathrm{~s}$, and $t_{f}$ can be considered to be uniformly distributed within this range.

(5) Intermittent operating sensors opening depth interval $\Delta h_{i}$ and running time $\Delta t_{i}$

The intermittent operating sensor carried by DeepArgo Otarriinae is only an altimeter that prevents
Deep-Argo Otarriinae from bottoming out. Too small opening depth interval of altimeter will greatly increase energy consumption while too large opening depth interval will easily cause Deep-Argo Otarriinae bottom out. Considering the diving speed of Deep-Argo Otarriinae and the buoyancy adjustment time, we set the altimeter opening depth 
interval $\Delta h_{i}$ to be uniformly distributed between $0 \mathrm{~m}$ and $50 \mathrm{~m}$. Similar to the altimeter opening depth interval, too short running time $\Delta t_{i}$ of the altimeter may cause Deep-Argo Otarriinae to bottom out while too long running time $\Delta t_{i}$ will increase the energy consumption. Considering the diving speed of Deep-Argo Otarriinae and the installation position of the altimeter, we set the running time $\Delta t_{i}$ to be uniformly distributed between 2 and $10 \mathrm{~s}$.

\section{Sensitivity Analysis of Energy Consumption Parameters}

5.1. Sensitivity Analysis Based on Sobol' Method. Sensitivity analysis (SA) aims to identify the key parameters that affect model performance, and it plays important roles in model parameterization, calibration, optimization, and uncertainty quantification [25]. Sensitivity analysis includes local sensitivity analysis (LSA) and global sensitivity analysis (GSA), where global sensitivity analysis is a common technique for evaluating the relative contribution of input parameters to the overall output by considering the change of input factors throughout the change space. Sobol' method is based on the variance decomposition first proposed by Sobol' [26], which is suitable for nonlinearity having many input variables and strong stability [27]. In recent years, it has been widely used in many fields including marine engineering [28-30].

Sobol' method estimates the importance of each input parameter by means of variance decomposition [31]. According to Sobol' method, the energy consumption model can be decomposed as follows:

$$
\begin{aligned}
Q= & f(X) \\
X= & \left(x_{1}, x_{2}, \ldots, x_{M}\right), \\
f(X)= & f_{0}+\sum_{i=1}^{M} f_{i}\left(x_{i}\right)+\sum_{1 \leq i \leq j \leq M}^{M} f_{i j}\left(x_{i}, x_{j}\right)+\cdots \\
& +f_{1,2 \ldots, M}\left(x_{1}, x_{2}, \ldots, x_{M}\right),
\end{aligned}
$$

where $f(X)$ is a function expression of the energy consumption model, $x_{1}, x_{2}, \ldots, x_{M}$ are $M$ independent input parameters affecting energy consumption, respectively.

Assuming that the square of $f(X)$ is integrable, the following equation can be obtained by squaring the left and right sides of equation (30) and then multiple integrals of input variables in space.

$$
\begin{aligned}
\int f^{2}(X) d X-f_{0}^{2}= & \sum_{i=1}^{M} \int f_{i}^{2}\left(x_{i}\right)+\sum_{1 \leq i \leq j \leq M}^{M} \int f_{i j}^{2}\left(x_{i}, x_{j}\right) \\
& +\ldots+\int f_{1,2, \ldots, M}^{2}\left(x_{1}, \ldots, x_{M}\right) .
\end{aligned}
$$

The left part of equation (30) is called the total variance, which can be described as

$$
D=\int f^{2}(X) d X-f_{0}^{2}
$$

where $D$ is total variance.

Each term on the right side of equation (30) is called partial variance. The single effect of $i-t h$ input parameter on the model output can be described as

$$
D_{i}=\int f_{i}^{2}\left(x_{i}\right)
$$

where $D_{i}$ is the single effect of $i-t h$ input parameter on the model output.

The joint effect of input parameters on the model output can be described as

$$
D_{i, j}=\sum_{1 \leq i \leq j \leq M}^{M} \int f_{i j}^{2}\left(x_{i}, x_{j}\right)+\ldots \int f_{1,2 \ldots, M}^{2}\left(x_{1}, x_{2}, \ldots, x_{M}\right) \text {, }
$$

where $D_{i j}$ is the joint effect of input parameters on the model output.

The main effect indices $S_{i}$ and the total effect indices $S_{T i}$ of the parameter $x_{i}$ to the model can be described as

$$
\begin{aligned}
S_{i} & =\frac{D_{i}}{D}, \\
S_{T_{i}} & =1-\frac{D_{\sim i}}{D},
\end{aligned}
$$

where $D_{\sim i}$ is the effect of all parameters but $x_{i}$.

The difference between the main effect and the total effect indices of the parameter $x_{i}$ is a measure of the interaction of $x_{i}$ with all other parameters. The main effect indices $S_{i}$ reflects effect on the model output when the parameter $x_{i}$ changes individually while the total effect indices $S_{T i}$ reflects the effect on the model output when the parameter $x_{i}$ interacts with other parameters. In addition, if the total effect indices of a parameter is close to 0 , we can assume that this parameter has no effect on the model output. GSA including the Sobol' method requires a large number of samples to ensure convergence of the calculation results. In order to get maximisation of the minimum interpoint Euclidean distance between any two sampled points, we used Latin hypercube sampling (LHS) method to design the sample space and the sample space size is $(n, M)$. The total number of model evaluations for the approximation of both the main and total effects indices is therefore equal to

$$
N=n \times(M+2),
$$

where $N$ is the total number of model evaluations, $n$ is the number of samples, and $M$ is the number of independent parameters obtained per sample.

5.2. Results of Simulation. Since the energy model established in this paper is complex and some parameters are constant, it is impossible and unnecessary to perform sensitivity analysis on each parameter. Therefore, only the parameters most concerned by the researchers are selected 
TABle 4: Parameters distribution range and distribution law.

\begin{tabular}{lcccc}
\hline Parameters & Minimum value & Maximum value & Unit symbol & Distribution \\
\hline $\mathbf{K}_{\mathbf{D} 0}$ & 19.04 & 28.56 & $\mathrm{~kg} / \mathrm{m}$ & Uniform \\
$\mathbf{K}_{\mathbf{D}}$ & 924.88 & 1387.32 & $\mathrm{~kg} / \mathrm{m}$ & $\mathrm{Uniform}$ \\
$\mathbf{K}_{\mathbf{L} 0}$ & 0.0845 & 0.1267 & $\mathrm{~kg} / \mathrm{m}$ & $\mathrm{Uniform}$ \\
$\mathbf{K}_{\mathbf{L}}$ & 53.3750 & 35.5834 & $\mathrm{~kg} / \mathrm{m}$ & $\mathrm{Uniform}$ \\
$\mathbf{v}$ & 0.05 & 0.20 & $\mathrm{~m} / \mathrm{s}$ & $\mathrm{Uniform}$ \\
$\xi$ & -7.76 & 7.51 & Deg & Uniform \\
$\mathbf{H}$ & 200 & 4000 & $\mathrm{M}$ & Uniform \\
$\mathbf{t}_{\mathbf{f}}$ & 600 & 1200 & $\mathrm{~S}$ & Uniform \\
$\Delta \mathbf{h}_{1}$ & 0 & 50 & $\mathrm{M}$ & Uniform \\
$\Delta \mathbf{t}_{1}$ & 2 & 10 & $\mathrm{~S}$ & Uniform \\
\hline
\end{tabular}

for sensitivity analysis. In Section 4, the range and distribution of the 10 parameters for sensitivity analysis have been determined, as shown in Table 4.

The number of independent parameters $M$ is 10 , and the effect indices of each parameter can be guaranteed to converge when the number of samples $n$ is 9600 . Therefore, the total number of model evaluations $N$ is 115200 according to equation (36). The simulation was conducted on a computer configured with $2.80 \mathrm{GHz}$ i7-7700HQ processor. The software we used was MATLAB 2019a with SAFE toolbox [32], which took a total time of 150s. We obtain the main effect indices and the total effect indices of the above 10 parameters to the energy consumption model, which is shown in Figures 11 and 12, respectively.

In Figures 11 and 12, the $x$ axis is the sampling times and $y$ axis is the normalized values of main effect or total effect. Besides, the values of main effect or total effect of each parameter tends to be stable and converged with the increase of sampling times, which means our sampling times is suitable and the result of the simulation is convinced. We can see that the sensitivity indices of hydrodynamic parameters and sensor sampling parameters are relatively close and the values are small. The results of Figures 11 and 12 are averaged and ranked by the magnitude of the total sensitivity indices as shown in Figure 13 and Table 5.

5.3. Analysis and Discussion. Analysis and discussion about the above simulation results are given as follows:

(1) Within the range of parameters studied in this paper, the gliding angle $\xi$, the diving depth $H$, and the gliding speed $v$ are at a fairly high level and have a significant impact on the energy consumption of Deep-Argo Otarriinae in a single profile. The higher values of $\xi, H$, and $v$ will increase energy consumption. In fact, these three parameters determine the key parameters such as input power of the hydraulic system and the running time of Deep-Argo Otarriinae, which have a good match with the actual application. The main effect indices and total effect indices of other energy consumption parameters are much smaller, indicating that their changes have limited impact on energy consumption.

(2) Among the three key parameters that affect the energy consumption, the diving depth $H$ is

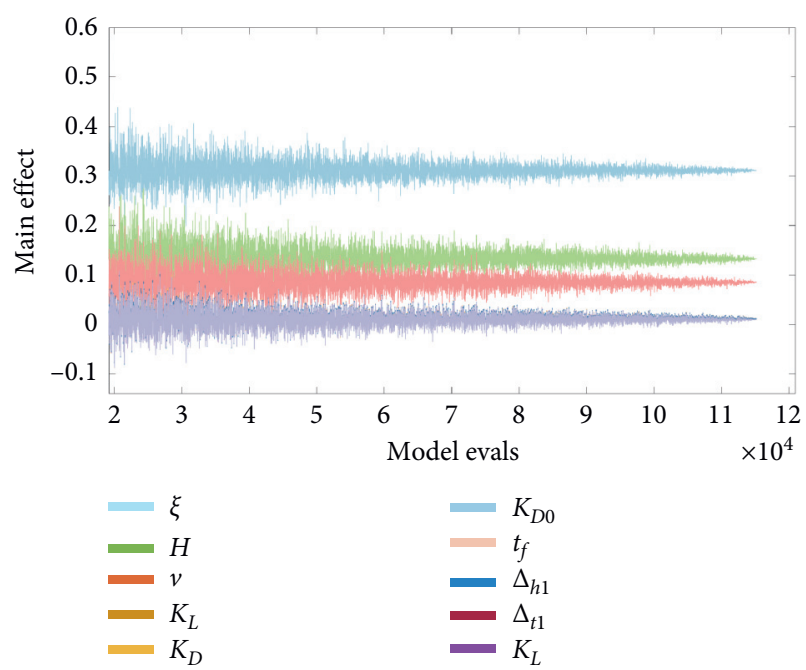

FIGURE 11: Results for main effect indices of each parameter with model evaluations.

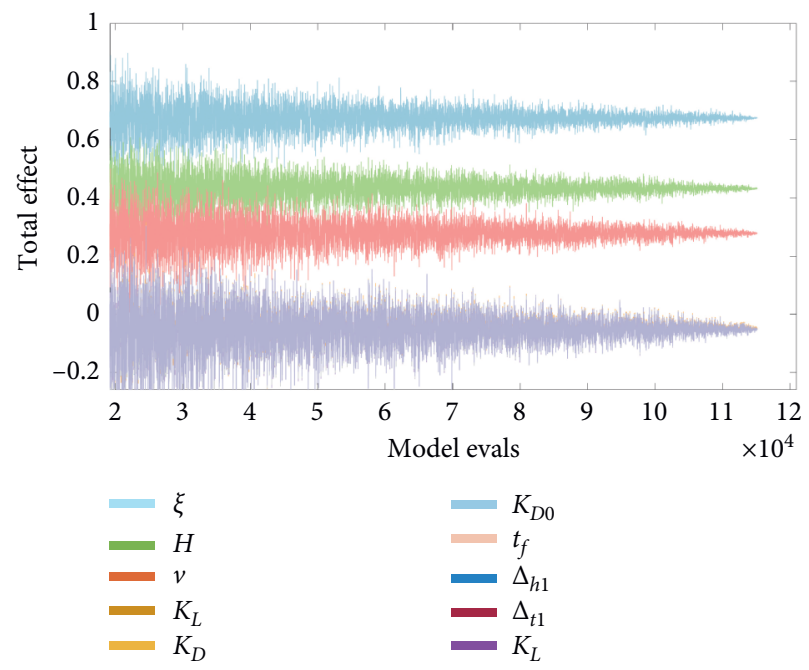

FIGURE 12: Results for total effect indices of each parameter with model evaluations.

completely set by operators according to the requirements of the working task. There are no posture adjust module and speed adjust module in our 


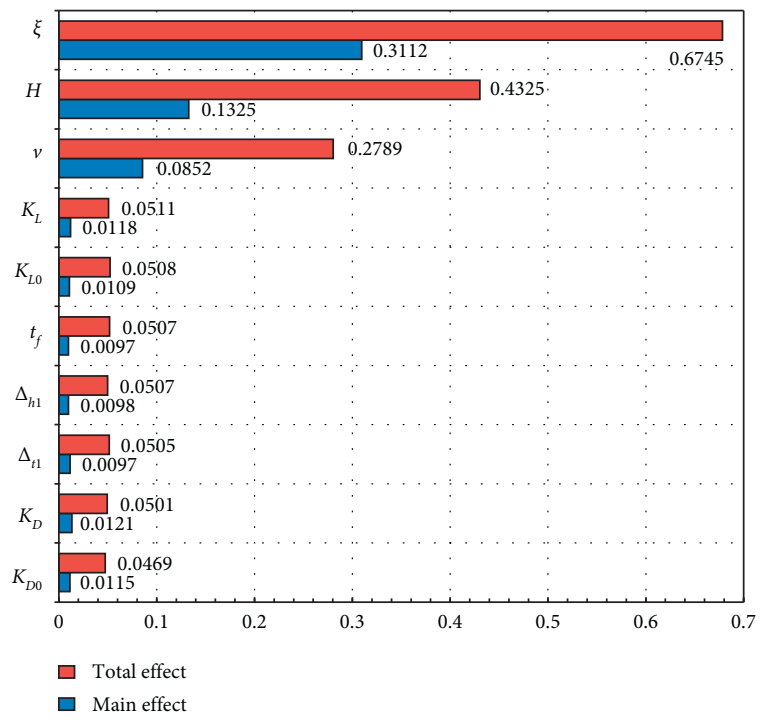

FIGURE 13: Results of the mean values for main effect and total effect with Sobol' method.

TABLE 5: Total effect and main effect of each energy consumption parameter.

\begin{tabular}{lccc}
\hline Order & Parameters & Total effect & Main effect \\
\hline 1 & $\xi$ & 0.6745 & 0.3112 \\
2 & $H$ & 0.4325 & 0.1325 \\
3 & $v$ & 0.2789 & 0.0852 \\
4 & $K_{L}$ & 0.0511 & 0.0118 \\
5 & $K_{L 0}$ & 0.0508 & 0.0109 \\
6 & $t_{f}$ & 0.0507 & 0.0097 \\
7 & $\Delta h_{1}$ & 0.0507 & 0.0098 \\
8 & $\Delta t_{1}$ & 0.0505 & 0.0097 \\
9 & $K_{D}$ & 0.0501 & 0.0121 \\
10 & $K_{D 0}$ & 0.0469 & 0.0115 \\
\hline
\end{tabular}

prototype. The gliding angle $\xi$ and gliding speed $v$ mainly depend on the volume, mass, and shape of Deep-Argo Otarriinae which have been determined during the design process. According to Table 5, we can see clearly that smaller hydrodynamic coefficients $K_{L}, K_{L 0}, K_{D}$, and $K_{D 0}$ will reduce the energy consumption of Deep-Argo Otarriinae. But smaller hydrodynamic coefficients will lead to a larger gliding speed which will increase energy consumption greater. Obtaining the optimal solution for hydrodynamic coefficients and gliding speed is a direction for future work.

(3) In order to reduce the energy consumption of DeepArgo Otarriinae, for designers, the simulation results above point out the optimization direction in the design process. Designers should focus on reducing the glide angle and the gliding speed through a large number of prototype pool experiments and hydrodynamic simulation. For operators, the simulation results show the influence of diving depth on energy consumption mathematically. When there is no mandatory requirement for the diving depth, operators should select the diving depth reasonably.

\section{Conclusions}

In this paper, a new modeling method for multiparameter energy consumption model of Deep-Argo Otarriinae was proposed. First, the kinematics model of Deep-Argo Otarriinae was established to show the relationship between various parameters. Then, the energy consumption of each subsystem of Deep-Argo Otarriinae in a single profile was calculated. Finally, an energy consumption model including hydraulic system parameters, navigation parameters, and other 19 parameters was established, which could describe the energy consumption of Deep-Argo Otarriinae in a single profile accurately and comprehensively. The energy consumption model we proposed contains many parameters and is highly nonlinear, which has certain research value and provides a new idea of multiparameter energy consumption modeling for underwater equipment using buoyancy regulation because their energy consumption components are similar. To reduce energy consumption of Deep-Argo Otarriinae and extend its working time, the Sobol' method was introduced to analyze the sensitivity of energy consumption parameters and the main effect indices and total effect indices of the selected parameters to energy consumption were calculated. The results of sensitivity analysis show that the gliding angle $\xi$, the diving depth $H$, and the glide speed $v$ have a greater impact on energy consumption. Therefore, reducing the gliding angle and the diving depth in the design and setting the diving depth reasonably in operation can reduce the energy consumption of Deep-Argo Otarriinae effectively.

Future work can be done by establishing a more accurate kinematics model which incorporates more parameters and obtaining the optimal solution for hydrodynamic coefficients and gliding speed in the design. Furthermore, we can study the relationship between energy consumption and diving depth or gliding speed to lay the foundation for further research on reducing energy consumption of DeepArgo Otarriinae.

\section{Data Availability}

The data used to support the findings of this study are included within the article.

\section{Conflicts of Interest}

The authors declare that there are no conflicts of interest regarding the publication of this paper.

\section{Authors' Contributions}

Weiwei SI and Yifan XUE contributed equally to this article.

\section{Acknowledgments}

This paper was supported by the Key Research and Development Program of Shandong Province (NO. 
2019GHY112077), the Guangdong Basic and Applied Basic Research Foundation (NO. 2019A1515110040), the Research Fund of State Key Laboratory of Ocean Engineering (Shanghai Jiaotong University) (NO. 1911), the Shandong Province Postdoctoral Innovation Project (NO. 201901001), the Laboratory for Marine Geology, Qingdao National Laboratory for Marine Science and Technology (NO. MGQNLM201806), the Shenzhen Science and Technology R\&D Foundation (NO. JCYJ20180305164217766), and the Qingdao Postdoctoral Applied Research Project. Gang Xue is the visiting research fellow of State Key Laboratory of Ocean Engineering. Shenzhen Research Institute of Shandong University is the primary supported department.

\section{References}

[1] D. Roemmich, M. H. Alford, H. Claustre et al., "On the future of argo: a global, full-depth, multi-disciplinary array," Frontiers in Marine Science, vol. 6, 2019.

[2] S. C. Riser, H. J. Freeland, D. Roemmich et al., "Fifteen years of ocean observations with the global Argo array," Nature Climate Change, vol. 6, no. 2, pp. 145-153, 2016.

[3] N. Haavisto, L. Tuomi, P. Roiha, S. M. Siiriä, P. Alenius, and T. Purokoski, "Argo floats as a novel part of the monitoring the hydrography of the bothnian sea," Frontiers in Marine Science, vol. 5, 2018.

[4] M. Kuusela and M. L. Stein, "Locally stationary spatio-temporal interpolation of Argo profiling float data," Proceedings of the Royal Society A: Mathematical, Physical and Engineering Sciences, vol. 474, no. 2220, p. 20180400, 2018.

[5] K. A. Mork, Øk Skagseth, and H. Søiland, "Recent warming and freshening of the Norwegian sea observed by argo data," Journal of Climate, vol. 32, no. 12, pp. 3695-3705, 2019.

[6] B. Sun, C. Liu, and F. Wang, "Global meridional eddy heat transport inferred from Argo and altimetry observations," Scientific Reports, vol. 9, no. 1, 2019.

[7] T. Wang, S. T. Gille, M. R. Mazloff, N. V. Zilberman, and Y. Du, "Numerical simulations to project argo float positions in the middepth and deep southwest pacific," Journal of Atmospheric and Oceanic Technology, vol. 35, no. 7, pp. 1425-1440, 2018.

[8] G. C. Johnson, S. G. Purkey, N. V. Zilberman, and D. Roemmich, "Deep Argo quantifies bottom water warming rates in the Southwest Pacific Basin," Geophysical Research Letters, vol. 46, no. 5, pp. 2662-2669, 2019.

[9] K. S. Johnson, L. Coletti, H. Jannasch, T. Martz, D. Swift, and S. Riser, "Long-term observations of ocean biogeochemistry with nitrate and oxygen sensors in apex profiling floats," in Proceedings of the Agu Fall Meeting, vol. 89, San Francisco, CA, USA, December 2008.

[10] D. Roemmich, J. T. Sherman, R. E. Davis, K. Grindley, M. McClune, and C. J. Parker, "Deep solo: a full-depth profiling float for the argo Program," Journal of Atmospheric and Oceanic Technology, vol. 36, no. 10, pp. 1967-1981, 2019.

[11] X. André, B. Moreau, and S. Le Reste, "Argos-3 satellite communication system: implementation on the arvor oceanographic profiling floats," Journal of Atmospheric and Oceanic Technology, vol. 32, no. 10, pp. 1902-1914, 2015.

[12] T. Kobayashi, K. Amaike, K. Watanabe et al., "Deep NINJA: a new float for deep ocean observation developed in Japan," in Proceedings of the IEEE Symposium on Underwater Technology and Workshop on Scientific Use of Submarine Cables and Related Technologies, IEEE, Tokyo, Japan, April 2011.
[13] Z. Liu, X. Wu, J. Xu et al., "China Argo project: progress in China Argo ocean observations and data applications," Acta Oceanologica Sinica, vol. 36, no. 6, pp. 1-11, 2017.

[14] S. Le Reste, V. Dutreuil, X. André et al., "Deep-Arvor: a new profiling float to extend the argo observations down to 4000m depth," Journal of Atmospheric and Oceanic Technology, vol. 33, no. 5, pp. 1039-1055, 2016.

[15] H. C. Woithe and U. Kremer, "Feature based adaptive energy management of sensors on autonomous underwater vehicles," Ocean Engineering, vol. 97, pp. 21-29, 2015.

[16] J. Yu, F. Zhang, A. Zhang, W. Jin, and Y. Tian, "Motion parameter optimization and sensor scheduling for the seawing underwater glider," IEEE Journal of Oceanic Engineering, vol. 38, no. 2, pp. 243-254, 2013.

[17] Y. Zhou, J. Yu, and X. Wang, "Path planning method of underwater glider based on energy consumption model in current environment," Lecture Notes in Computer Science, vol. 142-152, 2014.

[18] E. Kelasidi, K. Y. Pettersen, and J. T. Gravdahl, "Energy efficiency of underwater robots," IFAC-PapersOnLine, vol. 48, no. 16, pp. 152-159, 2015.

[19] D. Lu, R. Cui, and P. Wang, "Energy efficient path planning of autonomous underwater vehicles for environment modelling," in Proceedings of the International Conference on Multisensor Fusion and Information Integration for Intelligent Systems, pp. 1-6, IEEE, Beijing, China, September 2014.

[20] F. Yao, C. Yang, M. Zhang, and Y. Wang, "Optimization of the energy consumption of depth tracking control based on model predictive control for autonomous underwater vehicles," Sensors, vol. 19, no. 1, p. 162, 2019.

[21] Z. Li, Y. Liu, F. Guo, G. Xue, S. Li, and X. Li, "Multi-objective optimization of the shell in autonomous intelligent argo profiling float," Ocean Engineering, vol. 187, p. 106176, 2019.

[22] J. S. Geisbert, Hydrodynamic Modeling for Autonomous Underwater Vehicles Using Computational and Semi-empirical Methods, Master's Thesis, Virginia Polytechnic Institute and State University, Blacksburg, Virginia, 2007, https://hdl.handle.net/10919/33195.

[23] N. Zilberman and D. Roemmich, "SIO float lab," 2016, http:// www.argo.ucsd.edu/Deep_SOLO_AST16.pdf.

[24] S. Soylu, B. J. Buckham, and R. P. Podhorodeski, "Redundancy resolution for underwater mobile manipulators," Ocean Engineering, vol. 37, no. 2-3, pp. 325-343, 2010.

[25] X. Song, J. Zhang, C. Zhan, Y. Xuan, M. Ye, and C. Xu, "Global sensitivity analysis in hydrological modeling: review of concepts, methods, theoretical framework, and applications," Journal of Hydrology, vol. 523, pp. 739-757, 2015.

[26] I. M. Sobol, "On sensitivity estimation for nonlinear mathematical models," Institute for Mathematical Modelling, vol. 2, no. 1, pp. 112-118, 1990.

[27] F. Pianosi, K. Beven, J. Freer et al., "Sensitivity analysis of environmental models: a systematic review with practical workflow," Environmental Modelling \& Software, vol. 79, pp. 214-232, 2016.

[28] L. J. M. Peeters, G. M. Podger, T. Smith, T. Pickett, R. H. Bark, and S. M. Cuddy, "Robust global sensitivity analysis of a river management model to assess nonlinear and interaction effects," Hydrology and Earth System Sciences, vol. 18, no. 9, pp. 3777-3785, 2014.

[29] K. Menberg, Y. Heo, and R. Choudhary, "Sensitivity analysis methods for building energy models: comparing computational costs and extractable information," Energy and Buildings, vol. 133, pp. 433-445, 2016. 
[30] X. Cheng, G. Li, R. Skulstad et al., "Data-driven uncertainty and sensitivity analysis for ship motion modeling in offshore operations," Ocean Engineering, vol. 179, pp. 261-272, 2019.

[31] A. Saltelli and I. M. Sobol, "Sensitivity analysis for nonlinear mathematical models: numerical experience," Institute for Mathematical Modelling, vol. 7, no. 11, pp. 16-28, 1995, http:// mi.mathnet.ru/eng/mm1810.

[32] F. Pianosi, F. Sarrazin, and T. Wagener, "A matlab toolbox for global sensitivity analysis," Environmental Modelling \& Software, vol. 70, pp. 80-85, 2015. 